\title{
Laparoscopic gastrectomy for gastric adenocarcinoma. Long-term results
}

\author{
F. J. Ibáñez Aguirre, J. S. Azagra ${ }^{1,2}$, M. L. Erro Azcárate, M. Goergen ${ }^{1,2}$, P. Rico Selas ${ }^{1,3}$, \\ A. Moreno Elola-Olaso ${ }^{1,3}$, M. Clemares de Lama, P. de Simone ${ }^{1}$ and M. M. Echenique Elizondo ${ }^{4}$ \\ Department of Digestive Surgery. Hospital de Zumárraga. Guipúzkoa, Spain. ${ }^{1}$ Department of Surgery. CHU de \\ Charleroi, Belgium. ${ }^{2}$ Department of Surgery. Centre Hospitalier de Luxembourg. Luxembourg. ${ }^{3}$ Service of General and \\ Digestive Surgery and Transplantation of Abdominal Organs. University Hospital 12 de Octubre. Madrid, Spain. \\ ${ }^{4}$ University of País Vasco. School of Medicine. Teaching Unit of San Sebastián. Guipúzkoa, Spain
}

\begin{abstract}
Background: the objective of our paper is to report on the long-term results of patients with gastric cancer treated by mini-invasive surgery with "intention-to-treat" laparoscopy.

Patients and methods: between June 1993 and January 2006, 130 patients comprising 94 men and 36 women with gastric adenocarcinoma were prospectively selected by two surgical teams in three hospitals based on a prior agreement (CHU Charleroi, Belgium, Centre Hospitalier de Luxembourg and Zumárraga Hospital, Spain). Patients with adenocarcinoma of the cardia were excluded. Mean age of patients was 68 years (range, 37-85 years).

Results: post-operative mortality within 60 days of operation was 6 patients; 109 patients were therefore properly followed up for an average of 49 months (range, 2-153 months).

Average survival time for 10 non-resected patients was 4.5 months. Average survival rate for all 14 palliatively resected patients was 6.9 months. Actuarial 5-year survival rate for R0-type surgery was 35\%. Global actuarial 5-year survival rate after resective surgery was $31 \%$.

Conclusions: laparoscopic gastrectomy with any kind of lymphadenectomy is a major but safe operation with acceptable mortality and morbility rates in patients with advanced gastric cancer, usually in poor general condition. Laparoscopic gastrectomy for locally advanced cancers is equivalent to laparotomy as far as long-term oncological results are concerned.
\end{abstract}

Key words: Laparoscopy. Gastric adenocarcinoma. Gastrectomy. Lymphadenectomy. Oncological results.

Ibáñez Aguirre FJ, Azagra JS, Erro Azcárate ML, Goergen M, Rico Selas P, Moreno Elola-Olaso A, Clemares de Lama M, De Simone P, Echenique Elizondo MM. Laparoscopic gastrectomy for gastric adenocarcinoma. Long-term results. Rev Esp Enferm Dig 2006; 98: 491-500.

Recibido: 19-10-05.

Aceptado: 31-01-06.

Correspondencia: Fco. Javier Ibáñez Aguirre. Servicio de Cirugía General y Aparato Digestivo. Hospital de Zumárraga. B ${ }^{a}$ Argixao, s/n. $20700 \mathrm{Zu}-$ márraga. Guipúzcoa. Fax: 943035 063. e-mail: javibanez@euskalnet.net

\section{ABBREVIATIONS}

Total gastrectomy (TG); subtotal gastrectomy (STG); multiple organ failure (MOF); interventionist radiology (IR); lymph nodes (LN).

\section{INTRODUCTION}

A global 5-years survival rate of $10-30 \%$ in patients gastrectomized for gastric adenocarcinoma (1-3) is the most overwhelming proof of the low impact of current treatments, including resective surgery. This is the only treatment that guarantees a hope for cure. Technical aspects are constantly evolving to reduce particularly high pre- and post-operative mortality and morbidity (4-6). All this leads us to consider mini-invasive surgery as a tool which may well be worth evaluating with the goal of optimizing therapy for gastric cancer.

The aim of our paper is to report the long-term results of a prospective, non-randomized series of 130 patients with gastric adenocarcinoma, whose treatment included mini-invasive surgery as a surgical tool with "intentionto-treat" laparoscopy. The diagnosis of these patients was optimized by means of systematic staging laparoscopy. During this procedure, a definitive surgical treatment was decided upon - curative or palliative, or simply abstention from any therapeutical surgery.

\section{PATIENTS AND METHODS}

Between June 1993 and January 2006, 130 patients (94 men and 36 women) with gastric adenocarcinoma were prospectively included in this study by two surgical teams in three hospitals based on a prior agreement 
(CHU Charleroi, Belgium/Centre Hospitalier du Luxembourg, and Zumárraga Hospital, Spain).

Inclusion criteria were:

- The diagnosis of gastric adenocarcinoma had to be confirmed by anatomo-pathological examination.

-Patients in whom preoperative examinations did not reveal generalized disease.

-Patients with generalized disease during preoperative examinations in whom clinical complications (hemorrhage or obstruction) led us to perform palliative surgery.

-Absence of other cancer history.

-Patients who signed an informed consent for the surgical procedure and laparoscopic approach.

Patients with adenocarcinoma of the cardia as well as patients with gastric stump neoplasm after a previous gastrectomy were excluded, as we consider these tumors within a different category.

Average age of patients was 68 years (37-85 years). The surgical risk of patients included in this study was assessed according to ASA (American Society of Anesthesiologists) scores. Fourteen patients were ASA I; 48 ASA II; 65 ASA III, and 3 ASA IV.

During preoperative assessment, patients underwent standardized tests -blood tests including tumor markers, standard thoracic and abdominal x-ray examinations, electrocardiography, lung function tests, gastroduodenoscopy associated with biopsies and echoendoscopy, total body scan, barium examination of the esophagoduodenal tract, and bone radionuclide scintigraphy.

All of the patients received an antithrombotic prophylactic treatment with low molecular weight heparin derivatives $\left(\right.$ Clexane $\left.^{\circledast}\right)$ administered the night before surgery, and antibiotic prophylaxis (Cefuroxime ${ }^{\circledR}$ and Metronida$\mathrm{zol}^{\oplus}$ ) for wound infection starting at the time of anesthesia induction and maintained for 48 hours during the post-operative period.

In previous publications (7-10) we fully described the surgical techniques used for total or subtotal laparoscopicassisted gastrectomies. In the present article we shall merely describe the fact that all patients were submitted to a laparoscopic exploration of the whole peritoneal cavity, including the omental sac, in order to optimize staging and to adapt the surgical procedure. A laparoscopic ultrasound examination was also used at this stage as a complementary exploration (B\&K, Benelux Medical, Brussels, Belgium). When the above exploration discovered or confirmed the presence of peritoneal metastatic spread or hepatic metastasis, patients were not submitted to surgery "for curative purposes", but, depending on their clinical condition, underwent a laparoscopic gastrectomy for clean-out purposes or were subjected to complete surgical abstention.

Table I illustrates the final post-operative pathological stage of patients included in this study. Lauren's histological type as observed in this patient series was as follows: intestinal: 97, diffuse: 29, mixed: 4.

We used an SPSS software package for comparative statistical analysis.
Table I. Final post-operative staging

\begin{tabular}{lll}
\hline pTNM & UICC stage & No. of patients 101 \\
\hline TisNOMO & Stage 0 & 3 \\
T1NOMO & Stage Ia & 7 \\
T1N1MO & Stage Ib & 4 \\
T2NOMO & Stage Ib & 15 \\
T1N2MO & Stage II & 0 \\
T2N1MO & Stage II & 8 \\
T3NOMO & Stage II & 17 \\
T2N2MO & Stage IIla & 8 \\
T3N1MO & Stage IIla & 9 \\
T4NOMO & Stage IIla & 0 \\
T3N2MO & Stage IIIb & 26 \\
T4N1MO & Stage IV & 0 \\
T4N2MO & Stage IV & 4 \\
T4N3MO & Stage IV & 0 \\
T1N3MO & Stage IV & 0 \\
T2N3MO & Stage IV & 2 \\
T3N3MO & Stage IV & 3 \\
T N M1 & Stage IV & 24 \\
\hline Am & S & \\
\hline
\end{tabular}

American Joint Committee on Cancer (AJCC) Cancer Staging Manual. $5^{\text {th }}$ ed. Reprinted from http://tnm.uicc.org with the permission of John Wiley \& Sons, Inc.

Values are expressed as mean \pm SEM.

Global survival and disease-free survival were represented by means of a Kaplan-Meier-type analysis.

\section{RESULTS}

All 130 patients underwent stage-optimizing laparoscopy. In 7 cases we discovered a peritoneal spread undetected by preoperative examinations, and in other 3 cases we confirmed a previously suspected peritoneal involvement. No other surgical procedure was carried out on these 10 patients, who underwent palliative oncological treatment.

None of these patients showed differences between laparoscopic data and pTNM.

After proper staging, one hundred and twenty patients underwent a laparoscopic or video-assisted gastrectomy for curative (106 cases) or palliative purposes (14 cases) depending on tumor stage (UICC) and location (antral vs. body of stomach), and patient clinical condition (hemorrhage or antropyloric subobstruction).

Table II shows the type of "surgery" performed in these patients: a) 6 patients required an open conversion (5\%) -two at the beginning of the study- due to uncontrolled hemorrhage during lymphadenectomy on the left gastric artery, a site with important lymph node (ln) conglomerates; b) one by accidental jejunal injury; and c) another one due to the presence of a T4 tumor infiltrating the transverse colon and requiring total gastrectomy and right and transverse colectomy, and two pseudo-T4 tumors.

Four patients suffered "accidental injuries" during the procedure (3.3\%): a) an injury of the pancreatic body 
Table II. Surgical procedures

\begin{tabular}{lc}
\hline Adapted surgery after laparoscopic exploration & No. of patients \\
\hline Extended laparoscopic exploration & 130 \\
No surgery & 10 \\
Wedge resection & 2 \\
Total gastrectomy (TG)/subtotal gastrectomy (STG) palliative R2 & $10 / 4$ \\
D1- TG R0 & 15 \\
D2- TG R0 & 29 \\
D3- TG + Splenectomy RO / D2-TG + Splenectomy RO & $5 / 4$ \\
D1- STG distal R0 & 22 \\
D2- STG distal R0 & 29
\end{tabular}

D1: rate of perigastric lymphadenectomy (11); D2: rate of remote lymphadenectomy (11); D3: rate of inter aorto-cava lymphadenectomy (11); RO: curative surgery; R2: palliative surgery with tumoral residue in the affected zone. In the four T4 patients the following was associated: in one of them a right colectomy (in one of the reconverted patients) and a distal pancreatectomy, and two hepatic wedge resections also performed by means of laparoscopy.

caused by a retractor introduced through the mini-laparotomy at the time of esophago-jejunal anastomosis; b) an injury of the hepatic artery successfully repaired by means of laparoscopy and sutured with 5/0 Prolene under bulldog clamping; c) a jejunal injury requiring conversion; and d) an injury to the left liver lobe controlled by laparoscopy. We have included conversion cases in our study after considering that consequences are directly conditioned by the surgical approach.

Operations lasted for a significantly longer time in procedures of the D2- TG R0 type when compared to surgery of the D1- STG type: 310 vs. 170 minutes, with an average duration of $240 \pm 70$ minutes.

Postoperative mortality (at 60 days) occurred in 6 patients (5\%): a) two patients with liver cirrhosis who developed non-reversible acute hepatic failure; b) three multiple organ failures (MOFs), two after a duodenal stump fistula and one after acute pancreatitis developed in the patient suffering from the accidental pancreas injury; and c) one acute myocardial infarction.

Morbidity was represented by 38 complications (31.6\%). In the course of the observed complications 7 patients required reoperation and 6 were treated with interventionist radiology (IR). We observed the following complications: a) five duodenal stump fistulae, one belonging to the palliative surgery group. This patient was reoperated on -open surgery- given that no drain was placed during the laparoscopic intervention; b) three esophago-jejunal fistulae, one of which occurred in a patient in the palliative surgery group who was treated with IR; c) one gastro-jejunal fistula, reoperated because of peritonitis (laparoscopic approach); d) one gastro-jejunal stenosis reoperated on by open surgery; e) one hemorrhage reoperated on by means of the previous mini-laparotomy, revealing a bleeding point at the stapler line of the Roux-en-Y lateral suture; f) three deep abscesses, drained by IR; g) three pancreatitides: one due to pancreatic trauma during laparoscopy, which was reoperated by means of a laparotomy. This patient died due to MOF on the $5^{\text {th }}$ postoperative day; and h) two decompensated cirrhosis cases, who died on the $6^{\text {th }}$ and $9^{\text {th }}$ days, respectively, after surgery from MOF. Table III gives a detailed breakdown of morbidity and its related severity as seen in our series per procedure employed.

\section{Table III. Post-operative complications observed}

\begin{tabular}{lcccc}
\hline Complication & No. & Re-operated & IR & Mortality \\
\hline Pancreatitis & 3 & 1 & - & 1 \\
Duodenal fistula & 5 & 2 & - & 2 \\
Esophago-jejunal fistula & 3 & 1 & 1 & - \\
Gastro-jejunal fistula & 1 & 1 & - & - \\
Gastro-jejunal stenosis & 1 & 1 & - & - \\
P.o. hemorrhage & 1 & 1 & - & - \\
Pulmonary infection & 4 & - & - & - \\
Pleural effusion & 3 & - & 2 & - \\
Myocardial infarction & 1 & - & - & 1 \\
Decompensated cirrhosis & 2 & - & - & 2 \\
Pulmonary embolism & 1 & - & - & - \\
Urinary infection & 4 & - & - & - \\
Deep abscesses & 3 & - & 3 & - \\
Wall abscesses & 5 & - & - & - \\
Deep phlebothrombosis & 1 & - & - & - \\
\hline Total & $38(31.6 \%)$ & $7(5.8 \%)$ & $6(5 \%)$ & $6(5 \%)$ \\
\hline
\end{tabular}

No neoplastic implants were observed on laparoscopy trocar holes in our series.

In patients not suffering from serious complications, walking was allowed from the first day after surgery, and a liquid diet was authorized from the fifth day after surgery following a verification of esophago-jejunal or gastro-jejunal anastomoses with dye-enhanced (Gastrografin) X-ray examinations.

The mean postoperative stay of these patients was 10 days (6-38 days).

Regarding resected specimens, no cases of neoplasm were found on the pathology examination of surgical margins.

The average number of removed lymph nodes studied was $37 \pm 14$ ln in D2-TG-type gastrectomies, and $17 \pm 5$ LN in D1-STG-type gastrectomies.

Post-operative mortality within 60 days of operation occurred in 6 patients. Another 6 patients died during follow-up from reasons unrelated to their gastric cancers. Nine patients were lost to follow-up. Thus, 109 patients were properly followed up for an average of 49 months (2-153 months). Average survival time for all 10 non-resected patients was 4.5 months. Average survival time for all 10 palliatively resected patients was 6.9 months. Actuarial 5-year survival rate for R0-type surgery was 35\%, and global actuarial 5-year survival rate after resective surgery was $31 \%$. 


\section{DISCUSSION}

Laparoscopic surgery in gastric cancer is on the upswing in Japan. In this country, it is used as first-intention surgery on very early tumors -frequently found in the Far East- either as distal gastrectomies with limited and adapted lymphadenectomies or as wedge resection surgery, including endorganic surgery (11-14).

Different authors have reported on its technical feasibility and on the "safe" aspect of these operations, as indicated by its low morbidity rate and lack of operative mortality (15). Results published with a 10-year perspective demonstrate its oncological value with a global survival rate that is entirely comparable to that obtained with traditional surgery, but with optimized quality of life and minimum social cost (16-19).

This evolution in the choice of laparoscopy as a surgical means for treating early cancer is also seen in the West. Thus, the integral French report -published and validated in 2004 under the heading "Standards, Options et Recommandations 2003 pour la prise en charge des patients atteints d'adénocarcinome de l'estomac"- states that the resection of superficial gastric cancers or small adenocarcinomatous tumors is an option applicable in the framework of prospective studies (20).

The use of laparoscopy to treat locally advanced gastric cancers remains anecdotical, although certain authors have recently reported on their results (19,21-23).

From a technical point of view, our prospective, bicentric series carried out with an "intention-to-treat" laparoscopy design allows to scientifically state the feasibility of all kinds of laparoscopic gastrectomy with a low conversion rate (6 out of 120 cases of laparoscopic gastrectomy).

A laparoscopic approach means that D1-, D2- or D3level lymphadenectomies are totally comparable to those obtained by laparotomy, with an identical LN sample rate (11). Moreover, laparoscopy allows in any lymphadenectomy the preservation of the pancreas, thus guaranteeing minimum morbimortality, as demonstrated by earlier comparative series (24-26).

With $37 \%$ of IIIb and IV stages, our series once again shows a late diagnosis of gastric cancer in Western populations despite their easy access to medical care and a sophisticated diagnostic armamentarium (27). In these locally advanced tumors the results published in the literature concerning global follow-up and disease-free survival rates are poor, with a relapse rate ranging from 40 to $65 \%$, and an average survival rate of 24 months (28-30). Here, once again, our results $(31 \%$ of global survival rates in gastrectomized patients, and $35 \%$ in R0 gastrectomized patients) are entirely comparable with those obtained in traditional series. This means that, in terms of long-term survival, laparoscopic surgery obtains the same oncological results as laparotomic surgery in patients with locally advanced gastric adenocarcinomas.
Regarding post-operative mortality, while rates of up to $10 \%$ have been accepted and published $(4,5)$, our series, with a mortality of 5\%, confirms the "safe" character of laparoscopy for large and extended gastrectomies, whether or not associated with extended lymphadenectomies (24-26).

In our opinion, the $31.6 \%$ post-operative complication rate observed in our series reveals the impact of major surgery performed on patients with an often advanced cancerous disease $(4,5)$. Here too, as far as oncological results are concerned, laparoscopic surgery does not seem to reduce the complication rate observed in the laparotomy approach in these seriously impaired patients. The best proof of this is the high mortality and morbidity observed in the subgroup of patients submitted to paliative gastrectomy, in which the number of deaths and of serious complications seen within 60 days following operation is significantly increased $(3$ deaths out of 6 , and 10 complications from all $38 \mathrm{ob}-$ tained in the global series, belonging to the subgroup receiving resective palliative surgery) as indicated in table IV.

Table IV. Compared mortality and morbidity between palliative and curative resection

\begin{tabular}{lccc}
\hline & $\begin{array}{c}\text { Number of } \\
\text { patients }\end{array}$ & $\begin{array}{c}\text { Mortality within } \\
60 \text { days after } \\
\text { operation }\end{array}$ & $\begin{array}{c}\text { Morbidity within } \\
60 \text { days after } \\
\text { operation }\end{array}$ \\
\hline Palliative resections & 14 & $3(21.4 \%)$ & $10(71.4 \%)$ \\
Curative resections & 106 & $3(2.8 \%)$ & $28(26.4 \%)$ \\
\hline
\end{tabular}

In the Hüscher et al. reported series, where patients clearly show more favorable stages, the complication rate and the operative mortality observed were particularly low (23).

Two final observations help us to close the discussed analysis of our series:

- On the one hand, systematical laparoscopic staging as performed allowed us to avoid a pointless, and even abusive laparotomy in $7.7 \%$ of our patients, and urges from now on to select those patients whose imaging diagnosis does not allow the ruling out of generalized disease -being in these cases illusory to apply curative resection gestures. Staging laparoscopy would also be useful in the selection of patients for future neoadjuvant treatments, the efficacy of which have to be evaluated $(20,31,32)$.

- On the other hand, with an average post-operative hospital stay of 10 days, we believe that laparoscopic gastrectomy results in an optimal immediate post-operative quality of life in patients not suffering from serious complications. 


\section{CONCLUSIONS}

From the analysis of this non-randomized prospective series of 130 patients with locally advanced gastric adenocarcinoma (excluding cardial location), we conclude that: a) technically speaking, any type of gastrectomy with any kind of lymphadenectomy is feasible and reproducible by means of laparoscopy, with results that are totally comparable to those obtained by means of laparotomy; b) laparoscopic gastrectomy with any kind of lymphadenectomy is a severe but safe procedure, and gives acceptable mortality and morbidity rates in patients with locally advanced gastric cancer, generally in poor condition; c) laparoscopic gastrectomies for locally advanced cancers are equivalent to those performed by laparotomy as far as long-term oncological results are concerned; and d) it is likely that prospective and randomized studies directed to evaluate quality of life and global cost may give us better understanding on the true impact of laparoscopic surgery in the treatment of gastric cancer.

\section{REFERENCES}

1. Harrison L, Karpeth M, Brennan M. Extended lymphadenectomy is associated with a survival benefit for node-negative gastric cancer. J Gastrointest Surg 1998; 2: 126-31.

2. Msika S, Benhamiche A, Jouve JL, Rat P, Faivre J. Prognostic factors after curative resection of gastric cancer. A population-based study. Eur J Cancer 2000; 36: 390-6.

3. Green D, Ponce de León S, León-Rodríguez E, Sosa-Sánchez R. Adenocarcinoma of the stomach: univariate and multivariate analysis of factors associated with survival: Am J Oncol 2002; 25: 84-9.

4. Bonenkamp JJ, Hermans J, Sasako M, van der Veide CJ, Welvaart $\mathrm{K}$, Songun I, et al. Extended lymph node dissection for gastric cancer. Dutch Gastric Cancer Study. N Engl J Med 1999; 340: 908-14.

5. Cuschieri A, Weeden S, Fielding J, Bancewicz J, Craven J, Joypaul V, et al. Patient survival after D1 and D2 resections for gastric cancer: long term results of the MCR randomised surgical trial. Surgical Cooperative Group. Br J Cancer 1999; 79: 1522-30.

6. Kim JP. Current status of surgical treatment of gastric cancer. J Surg Oncol 2002; 79 (2): 79-80.

7. Azagra JS, Goergen M. Laparoscopic total gastrectomy. In: Meinero M, Melloti GL, Mouret Ph, editors. Laparoscopic Surgery: The Nineties. Milano: Masson; 1994. p. 289-96.

8. Azagra JS, Goergen M, de Simone P, Ibáñez-Aguirre JF. The current role of laparoscopic surgery in the treatment of benign gastroduodenal disease. Eur J Coelio-Surg 1997; 3: 41-6.

9. Azagra JS, Goergen M, de Simone P, Ibáñez-Aguirre JF. Minimally invasive surgery for gastric cancer. Surg Endosc 1999; 13: 351-7.

10. Azagra JS, Goergen M, Gilbart E, Alonso J, Ceuterick M. Laparoscopy-assisted total gastrectomy with extended lymphadenectomy for cancer: technical aspects. Le Journal de Coelio-chirurgie 2001; 40: 35-6.

11. Karpeh MS, León L, Klimstra D, Brennan MF. Lymph node staging in gastric cancer: is location more important than number? An analysis of 1038 patients. Ann Surg 2000; 232: 362-71.

12. Ohasi S. Laparoscopic intraluminal (intragastric) surgery for early gastric cancer. Surg Endosc 1995; 9: 169-71.

13. Ohgami M, Otani Y, Kumai K, Kubota T, Kim YI, Kitayima M. Curative laparoscopy surgery for early gastric cancer: five years experience. World J Surg 1999; 23: 187-92.

14. Kitano S, Shiraishi N. Current status of laparoscopic gastrectomy for cancer in Japan. Surg Endosc 2004; 18: 182-5.

15. Adachi Y, Shiraichi N, Shiromizu A, Bandoh T, Aramaki M, Kitano S. Laparoscopy-assisted Billroth-I gastrectomy compared with conventional open gastrectomy. Arch Surg 2000; 135: 806-10.

16. Kitano S, Shiraichi N, Kakisako K, Yasuda K, Inomata M, Adachi Y. Laparoscopy-assisted Billroth I-gastrectomy (LADG) for cancer: our 10 year's experience. Surg Laparosc Endosc Percut Tech 2002; 12: 204-7.

17. Maruyama K, Sasako M, Kinishita T, Sano T, Katai H, Hada M, et al. Should systemic lymph node dissection be recommended for gastric cancer? Eur J Cancer 1998; 34: 1480-3.

18. Adachi Y, Suematsu T, Shiraishi N, Katsuta T, Morimoto A, Kitano $\mathrm{S}$, et al. Quality of life after laparoscopy-assisted Billroth I gastrectomy. Ann Surg 1999; 229: 49-54.

19. Adachi Y, Shiraishi N, Ibeke K, Aramaki M, Bandoh T, Kitano S. Evaluation of the cost for laparoscopy-assisted Billroth I gastrectomy. Surg Endosc 1999; 15: 932-6.

20. Recommandations pour la pratique clinique. Standards, Options et recommandations 2003 pour la prise en charge des patients atteints d'adénocarcinome de l'estomac (cancers du cardias, autres types histologiques exclus): Rapport intégral. Available at: http://www.fnclcc/sor.htm.

21. Huscher CG, Mingoli A, Sgarzini G, Sansonetti A, Lirici MM, Napolitano C, et al. Videolaparoscopic total and subtotal gastrectomy with extended lymph node dissection for gastric cancer. Am J Surg 2004; 188 (4): 728-35.

22. Ibáñez-Aguirre JF, Goergen M, Bordas-Rivas JM, Azagra-Soria JS. Cirugía mínimamente invasiva en el cáncer gástrico. Cir Andal 2004; 15: 297-301.

23. Huscher CG, Mingoli A, Sgarzini G, Sansonetti A, di Paola M, Recher A, et al. Laparoscopic versus open subtotal gastrectomy for distal cancer: five-year results of a randomized prospective trial. Ann Surg 2005; 241 (2): 232-7.

24. Oñate-Ocaña LF, Aiello-Crocifoglio V, Mondragón-Sánchez R, RuizMolina JM. Survival benefit of D2 lymphadenectomy in patients with gastric adenocarcinoma. Ann Surg Oncol 2000; 7: 210-7.

25. Siewert JR, Bottcher K, Stein HJ, Roder JD. Relevant prognosis factors in gastric cancer: ten-year results of the German Gastric Cancer Study. Ann Surg 1998; 228: 449-61.

26. Marubini E, Bozzetti F, Miceli R, Bonfanti G, Gennari L. Lymphadenectomy in gastric cancer: prognostic role and therapeutic implications. Eur J Surg Oncol 2002; 28: 406-12.

27. Hundahl SA, Philips JL, Menck HR. The National Cancer Data Base Report on poor survival of US gastric carcinoma patients treated with gastrectomy: 5th ed. American Joint Committee on cancer staging, proximal disease, and the "different disease" hypothesis. Cancer 2000; 88: 921-32.

28. MacDonald J, Smalley S, Benedetti J, Hundahl SA, Estes NC, Stemmermann GN, et al. Chemoradiotherapy after surgery compared with surgery alone for adenocarcinoma of the stomach or gastroesophageal junction. N Eng J Med 2001; 345: 725-9.

29. Doglietto G, Pacelli F, Caprino P, Sgadari A, Crucitti F. Surgery: independent prognostic factor in curable and far advanced gastric cancer. World J Surg 2000; 24: 459-64.

30. Rigueiro Veloso MT, Rabuñal Rey R, Pértega Díaz S, Casariego Vales E, Pita Fernández E, Abraira V. Advanced gastric cancer: characteristics at presentation and therpeutic possibilities. Rev Esp Enferm Dig 2003; 95: 844-50.

31. Riva S, Muñoz-Navas M, Sola JJ. Gastric carcinogenesis. Rev Esp Enferm Dig 2004; 96: 265-76.

32. Dicken BJ, Bigam DL, Cas C, Mackey JR, Joy AA, Hamilton SM. Gastric adenocarcinoma: review and considerations for future directions. Ann Surg 2005; 241: 27-39. 